\title{
RESENHAS
}

\section{REINTERPRETANDO OS CICLOS DE APRENDIZAGEM}

Jefferson Mainardes

São Paulo: Cortez, 2007, 240p.

Mainardes, que já produziu outros textos marcantes da literatura sobre a organização do ensino em ciclos no Brasil, aporta neste estudo uma contribuição teórica inovadora ao procurar identificar, entre outros objetivos, a tessitura dos discursos que sustentam as políticas que ensejaram essa forma alternativa de escolarização. Além de examinar a bibliografia disponível sobre o tema no Brasil recorre à contribuição teórica de importantes autores do exterior, para explorar e problematizar impactos dos ciclos em uma rede municipal do Paraná, permitindo uma apreensão do processo de implementação da política que vai desde a elaboração da proposta até a chegada à sala de aula.

Apoiando-se em Richard Bowe e Stephen Ball, pesquisadores ingleses da área de políticas educacionais, Mainardes adota a "abordagem do ciclo de políticas" como referencial teórico-analítico para caracterizar como uma determinada política - no caso a de adoção de ciclos - é posta em movimento, desde sua gestação até sua inserção na prática, compreendidas suas interfaces e interdependências. Embora apresente as críticas que têm sido apontadas a esse modelo, considera que ele pode orientar análises da trajetória de políticas e programas educacionais sem incorrer em limitações de teorias que, ou são deterministas quanto ao papel do Estado, ou são localistas ao enfocarem apenas as conseqüências e apropriações das políticas em níveis mais imediatos. Para tanto, demarca três contextos principais: o de influência, o de produção do texto da política e o da prática. Além desses três contextos primários, o ciclo de políticas propõe que sejam analisados o contexto dos resultados ou efeitos - gerais ou específicos - e o contexto da estratégia política, que aponta para as atividades necessárias para lidar com eventuais desigualdades desencadeadas na implementação. Particularmente, destaca a política como texto e como discurso. Isto é, as propostas políticas têm uma dimensão textual ao codificar intenções e estabelecer com seus leitores um processo que, além de facultar reapropriações, pode sinalizar um caráter mais ou menos prescritivo. Como discurso, a política se configura como uma construção que expressa uma delimitação de interlocutores, além de estabelecer termos pertinentes e fixar critérios de valores na circulação e implementação dos seus objetivos, mas circulando num território de tensões.

Outor reporta-se também a conceitos formulados por Basil Bernstein, evocando as pedagogias invisíveis para dar conta dos procedimentos escolares difusos ou que não são completamente explicitados, como é o caso da avaliação pretensamente formativa. Pondera que a implantação dos ciclos, ao se chocar com as práticas avaliativas de caráter somativo, típicas das pedagogias visíveis e largamente empregadas no regime seriado, demandariam um conjunto de medidas que geralmente não têm sido atendidas, especialmente as relativas ao trabalho docente, o que termina reduzindo o potencial de benefício desse modelo.

O estudo procura evidenciar que os fundamentos das pedagogias invisíveis não se incorporaram mecanicamente às práticas pedagógicas apenas pelo anúncio de um discurso políti- 
co em favor dos ciclos, e constata que as pedagogias visíveis predominam na maioria das classes. Para o autor, "o modo como a política foi implementada ('de cima-para-baixo') e a falta de oportunidades legítimas de participação dos professores representaram obstáculos relevantes" (p.2I), confirmando achados semelhantes da literatura. Não seria, portanto, correto afirmar que há resistência dos professores aos ciclos, pois o que em geral sucede é uma produção textual e discursiva da política, que ignora, total ou parcialmente, outras vozes e interesses do processo educacional.

Retomando a perspectiva histórica, Mainardes argumenta que, no Brasil, desde os anos 1910 as políticas de não retenção passaram por sucessivas recontextualizações no campo pedagógico ou oficial, para usar a terminologia de Bernstein. $O$ campo pedagógico constituído por pedagogos que produzem pesquisas, formam novos profissionais e escrevem em periódicos, produziu um discurso de fundamentação dessas políticas, voltado para o seu caráter social, psicológico e pedagógico propriamente dito, e o campo oficial, constituído pelos gestores de políticas, produziu outro, freqüentemente mais voltado à economia dos recursos públicos. Em vários momentos esses campos convergiram para a implementação dessas políticas, mas em outros houve clara separação entre eles.

Analisando o discurso referente à política de ciclos, o autor argumenta que a consolidação do regime seriado, associado à implantação dos grupos escolares na virada do século XIX para o XX como expressão da política educacional do período republicano com vistas a organizar uma educação escolar de massas, logo evidenciou uma conseqüência: altas taxas de reprovação e evasão.

Salienta que nos anos 1950 assiste-se a um debate, sem grande correspondência com iniciativas práticas, que tem a promoção auto- mática dos alunos como destaque, demarcando uma separação entre os formuladores de políticas oficiais, dentre os quais se encontrava Anísio Teixeira, mais favoráveis à medida, e os intelectuais, dentre os quais o Luis Pereira, que apresentavam algumas ressalvas à sua adoção. Tal contenda atenua-se na década de 1960 e praticamente se extingue nos anos 1970, apesar de a Lei n. 5.692/7I mencionar a possibilidade de regimes escolares com "avanços progressivos", os quais foram introduzidos, por exemplo, em Santa Catarina desde o final dos anos 1960 e perduraram até 1984.

Embora tenha havido um conjunto de experiências que, sob denominações diversificadas, procuraram contornar o problema da reprovação mediante mecanismos de promoção automática ou assemelhados, é no início dos anos 1980 que o termo ciclo passa a ser empregado com o significado que genericamente se mantém até a atualidade. Com o ciclo básico de alfabetização no Estado de São Paulo, em 1984, depois adotado por Minas Gerais, Pará, Paraná e Goiás, o então ${ }^{\circ}$ grau tem suas duas primeiras séries organizadas num continuum destinado a propiciar aos alunos melhores condições de aprendizagem e, conseqüentemente, reduzir os níveis de reprovação e repetência. Neste contexto, há uma forte simbiose entre o campo oficial e o pedagógico, inclusive pela participação de intelectuais nos governos que adotavam essas medidas.

Nos anos 1990 ocorre uma diferenciação no próprio campo de recontextualização oficial, com a emergência de, pelo menos, duas vertentes de políticas de enfrentamento dos persistentes índices de reprovação. De um lado, os governos que defendiam os ciclos de formação, aparentemente mais progressistas, preconizando-os como uma alteração mais profunda e radical na organização da escola e do currículo do ensino fundamental. De outro, mais próximos da nova Lei de Diretrizes e Bases - LDB 
-, os que se atinham à progressão continuada, com uma visão mais conservadora do processo educacional, possivelmente por enfatizarem mais os aspectos relativos ao fluxo escolar e à racionalização de custos, sem propostas que tensionassem a seriação.

Nesse quadro, sobressai-se a iniciativa da rede municipal de ensino de São Paulo que, em 1992, rearticulou todo o ensino de $1^{\circ}$ grau em três ciclos de aprendizagem. Seguem-se então as iniciativas das redes municipais de Belo Horizonte (Escola Plural) e Porto Alegre (Escola Cidadã), que abrangem igualmente toda esta etapa da escolarização, mas ampliam a proposta para nove anos de ensino fundamental, organizados em três ciclos de três anos cada. Nestas duas redes foram adotados os ciclos de formação, baseados na noção de ciclo de desenvolvimento humano, como fator para definir a duração e organização de cada ciclo. Os ciclos de formação se distinguiriam dos ciclos de aprendizagem entre outros traços, pelo fato de focalizarem mais acentuadamente as características dos alunos e suas correspondentes faixas etárias, compreendidas do ponto de vista psicológico e cultural. Os ciclos de aprendizagem, ao contrário organizaram a escolarização com foco nas aprendizagens pretendidas, tal como tem formulado Philippe Perrenoud.

Quanto à progressão continuada, ressalta Mainardes que ela foi estabelecida na rede estadual paulista, a partir de 1998, com a adoção de dois ciclos de quatro anos cada, com a possibilidade de reprovação ao final desses. Em contraste com os discursos da política dos ciclos de formação, na rede paulista a estrutura das séries e seu correspondente conteúdo curricular não sofreu alterações mais profundas.

Na revisão da bibliografia sobre a temática dos ciclos no Brasil, o autor, demarcando as lacunas a serem superadas, constata que a maioria dos trabalhos (60\%) é de cunho teórico-crítico, e não traz evidências empíricas que ofereçam uma compreensão crítica das políticas de ciclos. As produções que procuram investigar aspectos de implementação acabam não articulando as questões locais com as macropolíticas, que permitiriam compreender de modo mais adequado tanto a caracterização do Estado, como também o próprio ciclo de políticas. Além disso, pela defesa assumida dos ciclos, há ainda o risco de se perder de vista a possibilidade de que, em determinadas condições de funcionamento, eles continuem a promover as desigualdades verificadas na seriação.

Mainardes apresenta a seguir os resultados de sua investigação de cunho etnográfico em uma rede municipal do Paraná, rede essa que adotou dois ciclos para suas escolas, que atendiam as séries iniciais do ensino fundamental, respectivamente com três e dois anos de duração, incluindo as crianças com seis anos de idade. Procura então identificar, segundo seu paradigma conceitual, o contexto de influência da política que o implementou.

A vitória de uma coalizão liderada pelo Partido dos Trabalhadores em 2000 propiciou um processo de recontextualização do campo político local. Este passou a reiterar a importância da escola no combate à exclusão social, defendida tanto pelo campo pedagógico, quanto pelas agências de fomento à educação, assim como pelas próprias políticas de ciclo desencadeadas pelo partido em várias localidades, com vistas ao enfrentamento do fracasso escolar. Contudo, a elaboração da proposta de ciclos, implementada em 200 I no município com redução drástica dos patamares de exclusão escolar, não contemplou setores sindicais e profissionais da educação, que tiveram baixa participação naquilo que Ball denomina "texto da política", ou seja, na sua formulação mais explícita. Isso aliás teria se manifestado inclusive nos documentos produzidos pela Secretaria Municipal de Educação, no quais preponderava o tom prescritivo. 
As evidências colhidas pela investigação em várias escolas da rede, nas quais "características essenciais da prática pedagógica da escola seriada estavam sendo reproduzidas na escola em ciclos", e o cotejamento da literatura levam o autor a destacar que, tanto pela própria formulação da política, como também pela desconsideração das profundas tarefas que precisam ser desencadeadas para a reversão das pedagogias visíveis, vários dos problemas relativos ao insucesso dos alunos na escola persistiram, a despeito de alguns ganhos para o conjunto da clientela escolar. Mainardes sugere ao final um conjunto de medidas que poderiam garantir aos alunos que não são reprovados nos ciclos um melhor aproveitamento escolar.

Não obstante fica no texto a constatação de que "[a] política de ciclos possui uma retórica progressista e, na maioria dos casos, tem sido implementada por partidos progressistas. Apesar disso, muitas vezes, a implementação dessa política não tem levado a avanços significativos no que se refere à consolidação de princípios e valores fundamentais, tais como democracia, igualdade e inclusão. $\bigcirc$ campo das pedagogias críticas no Brasil precisa ser reforçado tanto nos seus aspectos teóricos quanto práticos" (p. 194).

Trata-se de uma obra que traz contribuições importantes para a compreensão da política de ciclos, bem como suscita inúmeras questões e oferece pistas que podem ser mais bem exploradas em outras pesquisas.

Ocimar Munhoz Alavarse Doutor em Educação pela Universidade de São Paulo ocimarm@uol.com.br 